\title{
Comparing and Optimizing Nitrate Adsorption from Aqueous Solution Using Fe/Pt Bimetallic Nanoparticles and Anion Exchange Resins
}

\author{
Muhammad Daud, Zahiruddin Khan, Aisha Ashgar, M. Ihsan Danish, and Ishtiaq A. Qazi \\ Institute of Environmental Sciences and Engineering, School of Civil and Environmental Engineering, \\ National University of Sciences and Technology, Islamabad 44000, Pakistan
}

Correspondence should be addressed to Aisha Ashgar; aisha.iiui@yahoo.com

Received 23 February 2015; Revised 3 July 2015; Accepted 7 July 2015

Academic Editor: Jiazhi Yang

Copyright (C) 2015 Muhammad Daud et al. This is an open access article distributed under the Creative Commons Attribution License, which permits unrestricted use, distribution, and reproduction in any medium, provided the original work is properly cited.

\begin{abstract}
This research work was carried out for the removal of nitrate from raw water for a drinking water supply. Nitrate is a widespread ground water contaminant. Methodology employed in this study included adsorption on metal based nanoparticles and ion exchange using anionic resins. Fe/Pt bimetallic nanoparticles were prepared in the laboratory, by the reduction of their respective salts using sodium borohydride. Scanning electron microscope, X-ray diffraction, energy dispersive spectrometry, and X-ray florescence techniques were utilized for characterization of bimetallic Fe/Pt nanoparticles. Optimum dose, $\mathrm{pH}$, temperature, and contact time were determined for $\mathrm{NO}_{3}{ }^{-}$removal through batch tests, both for metal based nanoparticles and anionic exchange resin. Adsorption data fitted well the Langmuir isotherm and conformed to the pseudofirst-order kinetic model. Results indicated $97 \%$ reduction in nitrate by $0.25 \mathrm{mg} / \mathrm{L}$ of $\mathrm{Fe} / \mathrm{Pt}$ nanoparticles at $\mathrm{pH} 7$ and $83 \%$ reduction in nitrate was observed using $0.50 \mathrm{mg} / \mathrm{L}$ anionic exchange resins at $\mathrm{pH} 4$ and contact time of one hour. Overall, $\mathrm{Fe} / \mathrm{Pt}$ bimetallic nanoparticles demonstrated greater $\mathrm{NO}_{3}{ }^{-}$ removal efficiency due to the small particle size, extremely large surface area $\left(627 \mathrm{~m}^{2} / \mathrm{g}\right)$, and high adsorption capacity.
\end{abstract}

\section{Introduction}

Nitrate is the most widely available contaminant in ground and surface waters [1]. Excess of nitrate in drinking water results from anthropogenic sources, for example, overfertilization in agriculture, cattle shed discharge, untreated sewage, leakage from septic systems, infiltration of landfill leachate, and industrial waste water [2-5]. Out of these, synthetic fertilizers are the major contributors of nitrate pollution [6]. Nitrate concentration above the maximum permissible limit in drinking water is injurious to human health. Nitrate exposure can also lead to several health issues such as blue baby syndrome, increased infant mortality, birth defects, abdominal pain, diarrhea, vomiting, diabetes, hypertension, respiratory tract infections, and changes in the immune system [7-11]. To limit the risk to human health from nitrate in drinking water, the Maximum Contaminant Level (MCL) is set to be $10 \mathrm{mg} \mathrm{NO}_{3}{ }^{-} \mathrm{N} / \mathrm{L}$ ( $45 \mathrm{mg} \mathrm{NO}{ }_{3}^{-} / \mathrm{L}$ ) by USEPA, while the World Health Organization (WHO) and the European Community have set the MCL at $11.3 \mathrm{mg} \mathrm{NO}_{3}{ }^{-} \mathrm{N} / \mathrm{L}$ $\left(50 \mathrm{mg} \mathrm{NO}_{3}{ }^{-} / \mathrm{L}\right)[12,13]$. Numerous technologies are available for removal of nitrate from water. These include reverse osmosis, electrodialysis, biological denitrification, and ion exchange methods. In case of reverse osmosis (RO) water passes through a semipermeable membrane, and nitrate and other ions are rejected because their size is greater than the membrane pore size $[14,15]$. Biological denitrification is widely practiced for the treatment of municipal and industrial wastewater but is less commonly used in drinking water applications [16]. Ion exchange is a process in which the target ion gets exchanged with a loosely adsorbed ion on a resin. Ion exchange is also like a reversible chemical process in which ions from an insoluble permanent solid medium (the ion exchanger is usually a resin) are exchanged for ions in a solution [17]. This process is widely adopted for nitrate removal because of its simplicity, effectiveness, and 
relatively low cost [15-17]. Most of the on-going research has focused on nanosized zerovalent iron (NZVI) particles which typically have their size within the range of $1-100 \mathrm{~nm}$ $[18,19]$. The nanosized iron have larger surface area, about ten to hundreds times larger than microscopic iron powder, which results in more exposure of particles surface leading to enhanced adsorption efficiency [20].

NZVI supplemented with the secondary metal is a new technique for nitrate removal, which enhances the catalytic reactivity through hydrogenation $[21,22]$. Secondary metal also enhances reaction rate [23]. In order to improve the nitrate removal, various bimetallic nanoparticles were tested in batch studies and the most efficient combination of metals, that is, $(\mathrm{Fe} / \mathrm{Pt})$ nanoparticles, was compared with commonly used, strong base anionic exchange resins (Amberlite IRA402 $\mathrm{Cl}$ ). Langmuir and Freundlich isotherm models were used to study favorability of adsorption. To study kinetics of the chemical reactions pseudosecond-order kinetics model was applied.

\section{Materials and Methods}

2.1. Martials. Chemicals used in this research work included $\mathrm{NaBH}_{4}$ (Sigma-Aldrich), $\mathrm{FeCl}_{3} \cdot 6 \mathrm{H}_{2} \mathrm{O}$ (Merck), $\mathrm{FeSO}_{4} \cdot 7 \mathrm{H}_{2} \mathrm{O}$ (Merck), $\mathrm{PtCl}_{4}$ (Merck), PEG-4000 (Merck), and $\mathrm{CuSO}_{4} \cdot 6 \mathrm{H}_{2} \mathrm{O}$ (Merck). For solution preparation, known quantities of the compounds were dissolved in deionized water $\left(\mathrm{EC}<0.7 \mu \mathrm{S} / \mathrm{cm}\right.$, Labconco Waterpro PS). $\mathrm{KNO}_{3}$ was used for the nitrate solutions. For ion exchange experiments, strong base anion exchange resins (Amberlite IRA402 Cl) were purchased from Sigma-Aldrich. 0.1 M. Hydrochloric acid $(\mathrm{HCl})$ and sodium hydroxide $(\mathrm{NaOH})$ were used to adjust $\mathrm{pH}$ of the nitrate solutions. $10 \% \mathrm{NaCl}$ was used for regeneration of anionic exchange resins.

\subsection{Methodology}

2.2.1. Synthesis of Pt/Fe Bimetallic Nanoparticles. Fe/Pt bimetallic nanoparticles were synthesized in the laboratory in a Vacuum Glove Box (model: CV-1000 SAMPLATEC Corp., Japan) in an inert atmosphere. To synthesize Fe/Pt nanoparticles, $\mathrm{NaBH}_{4}(0.2 \mathrm{M}, 99 \%$ Aldrich $)$ solution was prepared in DI water/ethanol in $4: 1(\mathrm{v} / \mathrm{v})$ and added slowly at the rate of $2 \mathrm{~mL} / \mathrm{min}$ to $\mathrm{FeCl}_{3} \cdot 6 \mathrm{H}_{2} \mathrm{O}(0.05 \mathrm{M}, 99 \%$ Merck $)$ and $\mathrm{PtCl}_{4}(0.05 \mathrm{M}, 99 \%$ Merck) aqueous solution at $400 \mathrm{rpm}$ in nitrogen atmosphere in glove box. The solution was filtered using $0.45 \mu \mathrm{m}$ membrane filter in inert atmosphere to avoid contact of nanoparticles with air, prior to titration against $\mathrm{HNO}_{3}$. The resulting nanoparticles were washed thrice with distilled water and ethanol and stored in the dark.

2.2.2. Characterization of $\mathrm{Fe} / \mathrm{Pt}$ Bimetallic Nanoparticles. Bimetallic nanoparticles were analyzed through $\mathrm{X}$-ray diffraction (XRD, JEOL JDX-II, Japan). X-ray fluorescence analysis was performed using XRF-JEOL (Model JSX-3202M, Japan). The scanning electron microscope (JSM-6460, JEOL Ltd., Japan) attached with energy dispersive spectrometer (EDS, JSM-6460, JEOL Ltd., Japan) was used to find out surface morphology and composition of nanoparticles.
The porous texture characterization of the samples was recorded by $\mathrm{N}_{2}$ adsorption data at $-196^{\circ} \mathrm{C}$ (Autosorb-6B apparatus from Quantachrome [20]) the specific BET surface area $\left(S_{\mathrm{BET}}\right)$ was determined by applying using Brunauer-Emmett-Teller (BET) equation.

2.2.3. Batch Experiments Using Fe/Pt Bimetallic Nanoparticles. Batch experiments were carried out in $250 \mathrm{~mL}$ glass beaker covered with aluminum foil. All of the apparatus was covered, during experimentation, to restrict photocatalytic activity of nanoparticles and, moreover, to study adsorption efficiency of nanoparticles only. All experimental conditions optimization experiments were performed with $100 \mathrm{mg} / \mathrm{L}$ nitrate solutions. For dosage optimization, test solutions containing different concentrations of Fe/Pt bimetallic nanoparticles (0.1, 0.25, $0.50,0.75$, and $1 \mathrm{~g}$ ) were placed at an orbital shaker at $200 \mathrm{rpm}$ for one hour at room temperature. After dosage optimization, test solution with optimized dosage was tested at $200 \mathrm{rpm}$ for one hour, at three different $\mathrm{pH}$ levels (4, 7, and 10). Subsequent to dose and $\mathrm{pH}$ optimization, test solutions with optimized dosage were tested for different contact times (5, $10,15,20,30,45,60,90$, and $120 \mathrm{~min}$ ), with optimized dosage and optimized $\mathrm{pH}$. Finally, effect of temperature on removal efficiencies was studied at 15,25 , and $40^{\circ} \mathrm{C}$, with all other optimized conditions.

2.2.4. Batch Experiments Using Anionic Exchange Resins. Slurry based anionic exchange experiments were performed at different temperatures (i.e., 25,45 , and $60^{\circ} \mathrm{C}$ ), in $250 \mathrm{~mL}$ beaker containing nitrate solution added with varying quantities of anionic resin. Mixing was maintained by orbital shaker. After providing specific mixing time, the sample was filtered and tested. Parameters such as $\mathrm{pH}(4,7$, and 10), effect of initial nitrate concentrations $(10,25,50,100,200,300,400$, and $500 \mathrm{mg} / \mathrm{L})$ on removal efficiencies, and reaction times (5, $10,15,30,45,60,90$, and $120 \mathrm{~min})$ were investigated using spectrophotometer.

2.2.5. Adsorption and Kinetic Isotherm Experiments. In order to evaluate the surface properties and nanoparticles adsorption capacity, the experimental data were applied to the Langmuir equation. Isotherm experiments were performed with different initial nitrate concentration solution $(10-500 \mathrm{mg} / \mathrm{L})$, and the contact time of 1 hour, $\mathrm{pH}$ values of $4 \pm 0.05$, and temperature of $25^{\circ} \mathrm{C}$ were chosen as the experimental conditions to determine the adsorption isotherm of nitrate ions. For kinetic studies similar reaction conditions were used and reaction time was extended, till 2.5 hours, and samples were taken from time to time for final nitrate concentration analysis.

\section{Results and Discussion}

3.1. Characterization of Fe/Pt Bimetallic Nanoparticles. Characterization of Fe/Pt bimetallic nanoparticles is represented in Figure 1. The Pt is loaded at the surface of Fe nanoparticles, giving it a kind of bimetallic alloy nature. SEM images confirmed the presence of uniform spheroid, macroporous, sponge-like structure of high roughness and complexity. Such 


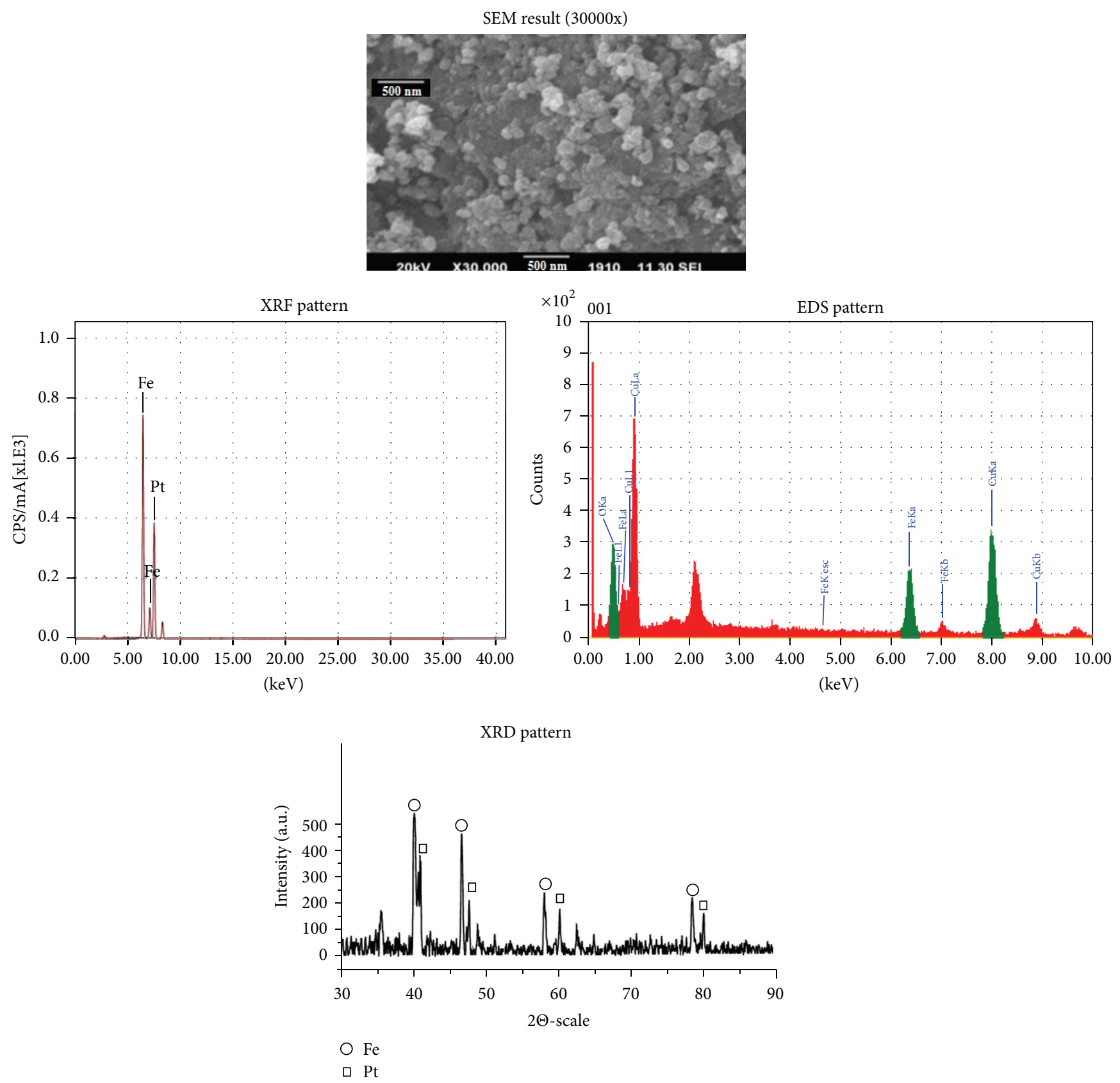

Figure 1: Characterization of Fe/Pt nanoparticles.

structure indicated the high surface area $\left(627 \mathrm{~m}^{2} / \mathrm{g}\right)$ which has been proven to be efficient for photocatalytic degradation purposes. XRF analysis confirmed that nanoparticles were composed of $\mathrm{Fe}$ and $\mathrm{Pt}$ metals in equimolar ratio. All of the samples show the superlattice reflections (001) and (110) as well as some splitting of the $(200) /(002)$ peak which signifies a tetragonality, as shown in Figure 1. EDS pattern revealed that the Fe/Pt nanoparticles were composed of almost $50 \%$ of each metal. X-ray diffraction was used to investigate the crystal phase composition bimetallic nanoparticles. XRD patterns showed that the nanoparticles contained pure anatase phase with the average crystallite sizes of 19 to $42 \mathrm{~nm}$.

\subsection{Experiment Conditions Optimization}

3.2.1. Effect of Adsorbent Dose. To study the removal efficiencies of adsorbent doses, $200 \mathrm{mg} / \mathrm{L}$ of the initial nitrate solution was used. Dosages for both anion exchange resin and $\mathrm{Fe} / \mathrm{Pt}$ bimetallic nanoparticles were varied among $100 \mathrm{mg} / \mathrm{L}$ to $1000 \mathrm{mg} / \mathrm{L}$, at $\mathrm{pH} 7$ within the contact time of $60 \mathrm{~min}$ for both adsorbents. It is clear from Figure 2 that $\mathrm{NO}_{3}{ }^{-}$removal is directly proportional to the absorbent dose till $500 \mathrm{mg} / \mathrm{L}$. Doses higher than $500 \mathrm{mg} / \mathrm{L}$ for resins and $250 \mathrm{mg} / \mathrm{L}$ for nanoparticles did not show significant $\mathrm{NO}_{3}$, so it would not be economical. The higher removal of nitrate was because of 


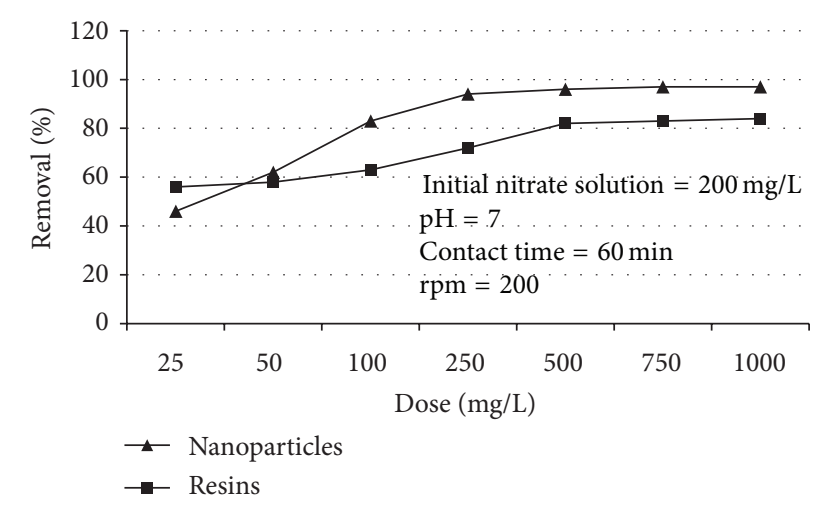

FIGURE 2: Effect of dose on nitrate removal by resins and $\mathrm{Fe} / \mathrm{Pt}$ bimetallic nanoparticles.

greater surface area of Fe/Pt nanoparticles requiring smaller dose as compared to anionic exchange resins.

3.2.2. Effect of $p H$. The effect of $\mathrm{pH}$ on nitrate removal using Fe/Pt bimetallic nanoparticles and anionic exchange resins was studied at three different $\mathrm{pH}$ values $(4,7$, and 10) with the optimized dosage $(0.50 \mathrm{mg} / \mathrm{L}$ resins, $0.25 \mathrm{mg} / \mathrm{L}$ nanoparticles) against $200 \mathrm{mg} / \mathrm{L}$ nitrate solution, within the contact time of one hour. Nitrate removal by Fe/Pt bimetallic nanoparticles and anionic exchange resins as a function of $\mathrm{pH}$ is shown in Figure 3. Results showed that, for anionic resin, nitrate was removed at all $\mathrm{pH}$ levels to a varying degree, at a contact time of 60 minutes. A maximum of $82.5 \%$ removal was achieved, using resin at $4 \mathrm{pH}$. Nitrate reduction efficiency by resins decreased notably with raising $\mathrm{pH}$ of the solution. The removal efficiency of nanoparticles, after contact time of $60 \mathrm{~min}$ and $\mathrm{pH}$ value of $4-10$, varied between 92 and $83 \%$. Rate of nitrate removal at $\mathrm{pH} 7$ was distinctively higher than for $\mathrm{pH} 4$ or 10.

3.2.3. Effect of Contact Time. Effect of adsorption of nitrate on $\mathrm{Fe} / \mathrm{Pt}$ nanoparticles and anionic exchange resins as a function of contact time of absorbents is shown in Figure 4. A pH 7 was maintained for nanoparticles and $\mathrm{pH} 4$ for anionic exchange resins. Optimized dose of each adsorbent was used for initial $200 \mathrm{mg} / \mathrm{L}$ nitrate solution. As reflected from the results, with increasing reaction time, the nitrate removal efficiency increased, for both adsorbents.

The distinct slopes in Fe/Pt nanoparticles curve showed that overall adsorption characteristics of nanoparticles changed with contact time over $45 \mathrm{~min}$ and continuously yielding slope reflected that extension in contact time would not have any dramatic effect on $\mathrm{NO}_{3}$ removal. The ion exchange resin however smoothly exhausted at about $70 \mathrm{~min}$. This also confirmed that minimum contact time of 60 minutes used in this experiment would be logical. For the contact time of $60 \mathrm{~min}$, nitrate removal efficiency was $91 \%$ vis-à-vis $83 \%$ under all other optimized conditions and the same contact time.

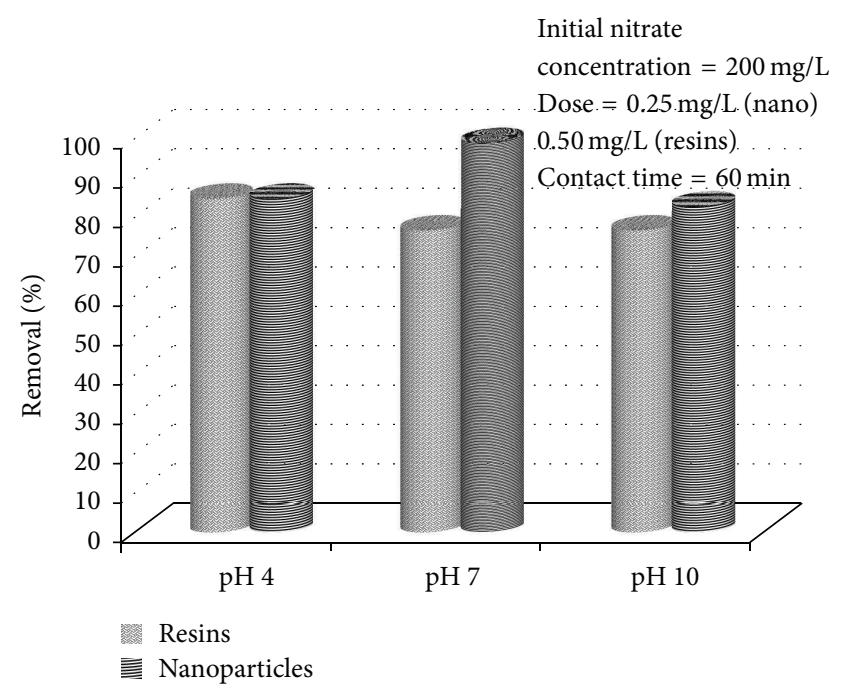

FIgure 3: Effect of $\mathrm{pH}$ on nitrate removal by resins and $\mathrm{Fe} / \mathrm{Pt}$ bimetallic nanoparticles.

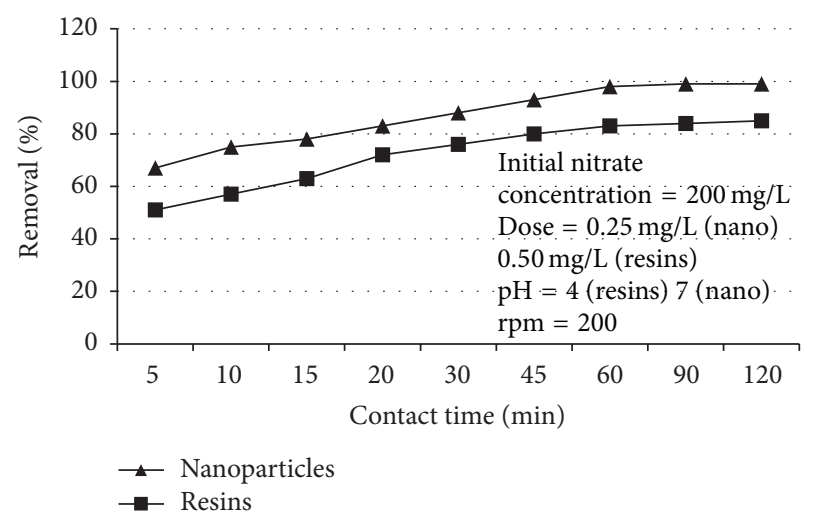

FIGURE 4: Effect of contact time on nitrate removal by resins $\mathrm{Fe} / \mathrm{Pt}$ bimetallic nanoparticles.

3.2.4. Effect of Temperature. The effect of temperature on nitrate was studied using optimized dosage, $\mathrm{pH}$, and contact time, against $200 \mathrm{mg} / \mathrm{L}$ nitrate solution at three different temperatures, that is, 15,25 , and $35^{\circ} \mathrm{C}$. Figure 5 shows the results. The effect of temperature on nitrate removal via anionic exchange resins indicated that nitrate removal increased, by increasing temperature. For Fe/Pt nanoparticles, during contact time of $60 \mathrm{~min}$ and at temperature $25^{\circ} \mathrm{C}$, about $87-90 \%$ of nitrate was removed. For resin rise in temperature up to $35^{\circ} \mathrm{C}$ helps improving $\mathrm{NO}_{3}$ removal. For Fe/Pt bimetallic nanoparticles, rise in temperature lowers $\mathrm{NO}_{3}$ removal efficiency.

3.2.5. Effect of Initial Nitrate Concentration. In the batch experimentation using anionic resin, the adsorption efficiency of resins under all other optimized conditions decreased from $83 \%$ to $48 \%$, when the initial nitrate concentration increased from 10 to $400 \mathrm{mg} / \mathrm{L}$ as shown in Figure 6. For similar changes in initial concentration of nitrate, with 


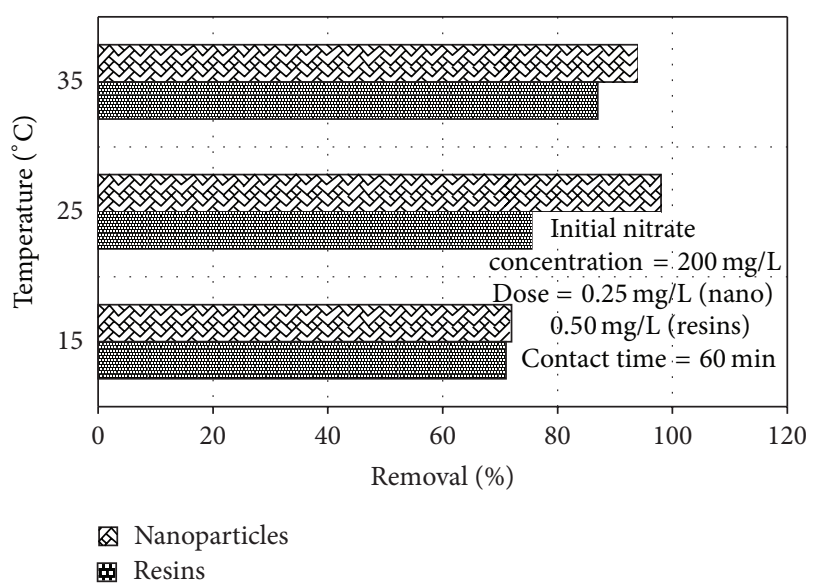

FIGURE 5: Effect of temperature on nitrate removal by resins and $\mathrm{Fe} / \mathrm{Pt}$ bimetallic nanoparticles.

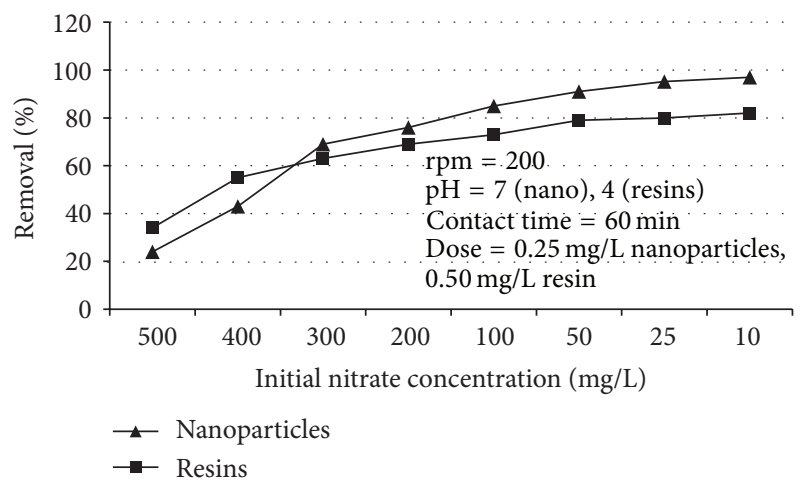

FIGURE 6: Effect of initial nitrate concentration and its removal by resin and $\mathrm{Fe} / \mathrm{Pt}$ bimetallic nanoparticles.

$\mathrm{Fe} / \mathrm{Pt}$ nanoparticles and nitrate adsorption efficiency gradually reduced from $98 \%$ to $51 \%$.

It seems to be an ion exchange resin support ion exchange phenomenon, till the $\mathrm{NO}_{3}{ }^{-}$concentration rises beyond its exchange capacity. There is however a smooth reduction in $\mathrm{Fe} / \mathrm{Pt}$ nanoparticle effectiveness with increase in initial concentration of $\mathrm{NO}_{3}$.

\subsection{Adsorption and Kinetic Isotherms}

3.3.1. Langmuir Isotherm. Capacity of the adsorbent can be estimated by adsorption studies. In order to evaluate the surface properties and resins adsorbent or exchange capacity the experimental data of varying initial nitrate concentrations was applied to the Langmuir equations. The linear Langmuir adsorption isotherms of nitrate ions are illustrated in Figure 7. The Langmuir parameters, $q_{m}$ and $b$, are calculated from the slope and intercept of the graphs and are given in Table 1. The linear fitting of models was examined by calculation of correlation factors $\left(R^{2}\right)$. The correlation values are also given in Table 1 . These values for Langmuir constants are higher in case of $\mathrm{Fe} / \mathrm{Pt}$ bimetallic nanoparticles indicating that Langmuir isotherm better fits adsorption data
TABLE 1: Langmuir isotherms constants of nitrate ions adsorption by nanoprticles and resins.

\begin{tabular}{lcccc}
\hline Materials & $q_{m}(\mathrm{mg} / \mathrm{g})$ & $b$ & $R_{L}$ & $R^{2}$ \\
\hline Resins & 83.55 & 0.057 & 0.08 & 0.984 \\
Fe/Pt nanoparticles & 103 & 0.647 & 0.01 & 0.998 \\
\hline
\end{tabular}

of nanoparticles, compared to the resin. Data clearly suggests that the adsorption of nitrates ions is monolayer-type in both cases; moreover, it agrees with the observation that the adsorption from an aqueous solution usually forms a layer on the adsorbent surface. The higher values of Langmuir constant $b$ shows the enhanced affinity of binding sites and suggests that a chemical interaction between adsorbent and adsorbate occurs much better in case of nanoparticles. The $R_{L}$ values (see Table 1) are all found to be within 0 and 1 indicating a highly favorable adsorption of nitrate ions onto ion exchange resins.

The Langmuir model assumes that adsorption occurs in monolayer or that adsorption may only occur at fixed number of localized sites on the surface with all adsorption sites identical and energetically equivalent.

3.3.2. Kinetic Isotherms. Adsorption kinetics determines the efficiency of adsorption; therefore, pseudosecond-order kinetic model was applied on the adsorption data. The correlation coefficients values indicate that the experimental data fits the kinetic model as shown in Figure 8.

Results explicitly explain that nitrate adsorption on nanoparticles and resins is a function of time and $\mathrm{pH} 4$. For a $200 \mathrm{ppm}$ initial nitrate concentration and reins dose of $0.5 \mathrm{mg} / \mathrm{L}, 12 \%$ of the total nitrate was removed after the first $5 \mathrm{~min}$; this value promptly increased to about $53 \%$ after $20 \mathrm{~min}$. After $120 \mathrm{~min}$, the maximum removal was $97 \%$. Nitrate adsorption on bimetallic nanoparticles is also a function of contact time and dose at $\mathrm{pH} 7$ as removal efficiency increased with the increase of contact time. For a 200 ppm initial nitrate concentration and bimetallic nanoparticles dose of $0.25 \mathrm{mg} / \mathrm{L}$, after the first $5 \mathrm{~min}, 15.5 \%$ of the total nitrate was removed and removal percentage drastically increased to about $68 \%$ after $20 \mathrm{~min}$. After $120 \mathrm{~min}$ the maximum removal was $83.5 \%$. Parameters for kinetic isotherm for both adsorbents are represented in Table 2, and all values are higher in case of nanoparticles, compared to resins. It is clear from the results that adsorption using nanoparticles gives much better removal efficiency.

\section{Conclusions}

The overall results indicate that $\mathrm{Fe} / \mathrm{Pt}$ nanoparticles having a large surface area $\left(627 \mathrm{~m}^{2} / \mathrm{g}\right)$ are potentially more efficient than the commercially used anionic resins for nitrate removal from water. Literature review demonstrates that, in bimetallic system, $\mathrm{Fe}$ is considered reductant for water to generate hydrogen, and the second metal, that is, $\mathrm{Pt}$, which has a high ability to dissociate $\mathrm{H}_{2}$ acts as catalyst [24]. For hydrochlorination of halogenated compounds, the coating of 


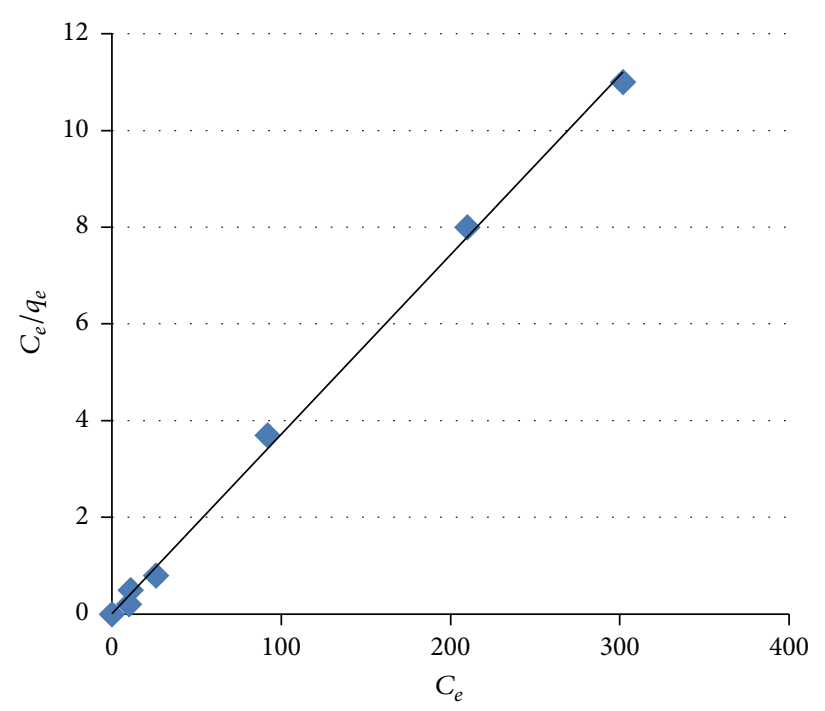

(a)

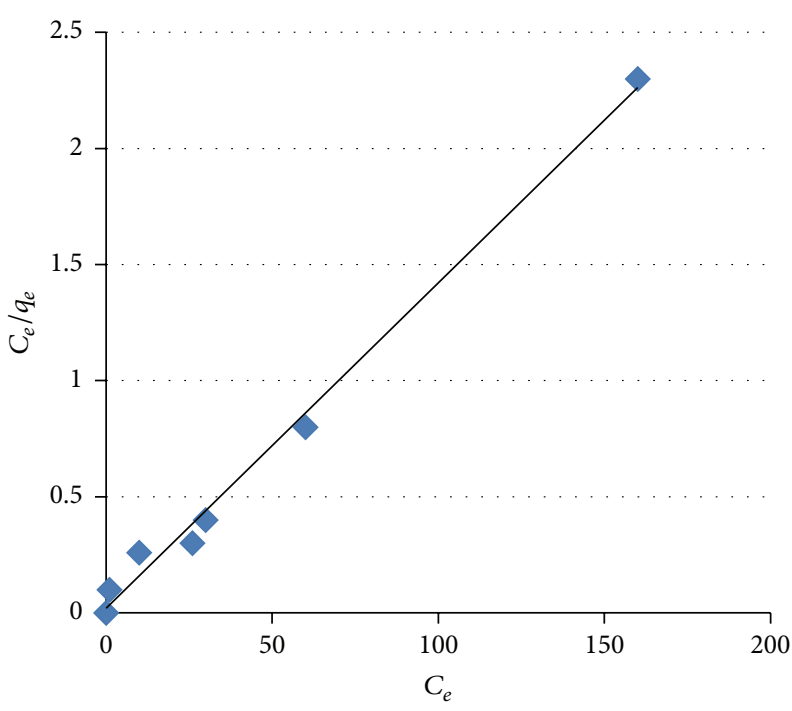

(b)

Figure 7: Langmuir adsorption model for (a) Fe/Pt bimetallic nanoparticles $25 \pm 1^{\circ} \mathrm{C}$ and (b) resins at $35 \pm 1^{\circ} \mathrm{C}$.

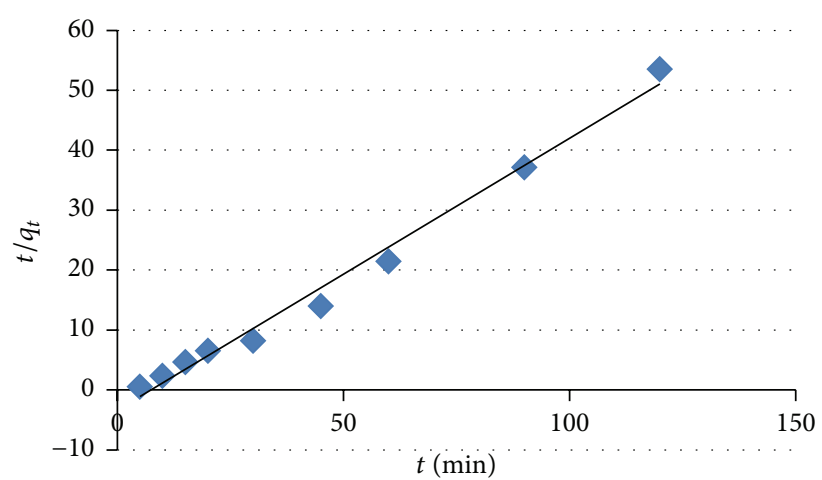

(a)

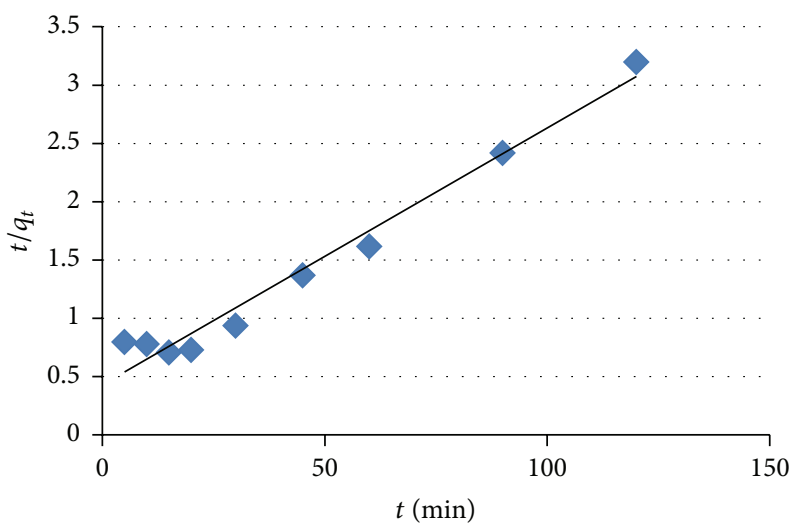

(b)

Figure 8: Pseudosecond-order kinetics model for (a) Fe/Pt bimetallic nanoparticles and (b) resins at $25 \pm 1^{\circ} \mathrm{C}$.

TABle 2: Pseudosecond-order kinetic plots for the adsorption of nitrate ions on nanoparticles.

\begin{tabular}{lccc}
\hline Materials & $q_{e}(\mathrm{mg} / \mathrm{g})$ & $K(\mathrm{~g} / \mathrm{mg} \mathrm{min})$ & $R^{2}$ \\
\hline Fe/Pt nanoparticles & 45.45 & 0.432 & 0.973 \\
Resins & 22.075 & 0.146 & 0.984 \\
\hline
\end{tabular}

secondary metal not only enhances the reactivity but also lowered the accumulation of toxic byproducts. Presence of $\mathrm{Pt}$ dramatically increased the reactivity of Fe nanoparticles for nitrate reduction.

During the catalytic reduction process of nitrate, nitrite was tested as intermediate product with the trend of first rising and then decreasing; no nitrite existed in solution at the end of reaction. This indicates that nitrate reduction with $\mathrm{Fe} / \mathrm{Pt}$ nanoparticles undergoes two steps: firstly, nitrate is adsorbed to nanoparticles surface and afterward is reduced to nitrite; as a result of strong affinity of particles surface to nitrite, only a little nitrite was detected in the solution during the reaction. Finally adsorbed nitrite reduced to ammonium followed by desorption of ammonium due to the weak affinity between $\mathrm{Fe} / \mathrm{Pt}$ bimetallic particles surface and ammonium [25].

Adsorption of nitrate was determined to be a pseudofirstorder reaction, with rates influenced by the initial concentration of the nitrate; furthermore, adsorption rate using nanoparticles were maximum at $7 \mathrm{pH}$ and $25^{\circ} \mathrm{C}$ with an optimized nanoparticles dose of $0.25 \mathrm{mg} / \mathrm{L}$. While adsorption results generated for both adsorbents fitted well the Langmuir isotherm, all Langmuir constants showed higher values in case of nanoparticles. Using optimized adsorption conditions resins showed maximum $83 \%$ removal; however, nanoparticles gave $97 \%$ nitrate removal for an initial nitrate solution of $200 \mathrm{mg} / \mathrm{L}$ in water. Experiments are currently underway (at IESE, NUST) in attempt to test and to study adsorption 
and photocatalytic effect of $\mathrm{Pt} / \mathrm{Fe}$ bimetallic nanoparticles on other ions present in waste water, through rapid small scale filter column tests.

\section{Conflict of Interests}

The authors declare that there is no conflict of interests regarding the publication of this paper.

\section{Acknowledgment}

The authors gratefully acknowledge financial support from the National University of Science and Technology, Islamabad, Pakistan.

\section{References}

[1] A. Liu, J. Ming, and R. O. Ankumah, "Nitrate contamination in private wells in rural Alabama, United States," Science of the Total Environment, vol. 346, no. 1-3, pp. 112-120, 2005.

[2] A. Nuhoglu, T. Pekdemir, E. Yildiz, B. Keskinler, and G. Akay, "Drinking water denitrification by a membrane bio-reactor," Water Research, vol. 36, no. 5, pp. 1155-1166, 2002.

[3] F. Hell, J. Lahnsteiner, H. Frischherz, and G. Baumgartner, "Experience with full-scale electrodialysis for nitrate and hardness removal," Desalination, vol. 117, no. 1-3, pp. 173-180, 1998.

[4] S. Samatya, N. Kabay, Ü. Yüksel, M. Arda, and M. Yüksel, "Removal of nitrate from aqueous solution by nitrate selective ion exchange resins," Reactive and Functional Polymers, vol. 66, no. 11, pp. 1206-1214, 2006.

[5] S. K. Nataraj, K. M. Hosamani, and T. M. Aminabhavi, "Electrodialytic removal of nitrates and hardness from simulated mixtures using ion-exchange membranes," Journal of Applied Polymer Science, vol. 99, no. 4, pp. 1788-1794, 2006.

[6] M. G. Rupert, "Decadal-scale changes of nitrate in ground water of the United States, 1988-2004," Journal of Environmental Quality, vol. 37, no. 5, pp. S240-S248, 2008.

[7] D. Majumdar and N. Gupta, "Nitrate pollution of groundwater and associated human health disorders," Indian Journal of Environmental Health, vol. 42, no. 1, pp. 28-39, 2000.

[8] B. C. Kross, A. D. Ayebo, and L. J. Fuortes, "Methemoglobinemia: nitrate toxicity in rural America," American Family Physician, vol. 46, no. 1, pp. 183-188, 1992.

[9] L. Fewtrell, "Drinking-water nitrate, methemoglobinemia, and global burden of disease: a discussion," Environmental Health Perspectives, vol. 14, no. 112, pp. 1371-1374, 2004.

[10] F. R. Greer and M. Shannon, "Infant methemoglobinemia: the role of dietary nitrate in food and water," Pediatrics, vol. 116, no. 3, pp. 784-786, 2005.

[11] M. H. Ward, T. M. deKok, P. Levallois et al., "Workgroup report: drinking-water nitrate and health-recent findings and research needs," Environmental Health Perspectives, vol. 113, no. 11, pp. 1607-1614, 2005.

[12] P. J. Squillace, J. C. Scott, M. J. Moran, B. T. Nolan, and D. W. Kolpin, "VOCs, pesticides, nitrate, and their mixtures in groundwater used for drinking water in the United States," Environmental Science and Technology, vol. 36, no. 9, pp. 19231930, 2002.

[13] World Health Organization, Revisions of the WHO Guidelines for Drinking Water Quality Report on a WHO Consultation, WHO Regional Office for Europe, Medmenham, UK, 1992.
[14] J. M. Symons, L. C. Bradley Jr., and T. C. Cleveland, The Drinking Water Dictionary, AWWA, McGraw-Hill, New York, NY, USA, 2001.

[15] MWH, Water Treatment Principles and Design, John Wiley \& Sons, Hoboken, NJ, USA, 2005.

[16] A. Kapoor and T. Viraraghavan, "Nitrate removal from drinking water review," Journal of Environmental Engineering, vol. 123, no. 4, pp. 371-380, 1997.

[17] A. Darbi, T. Viraraghavan, R. Butler, and D. Corkal, "Pilot-scale evaluation of select nitrate removal technologies," Journal of Environmental Science and Health, vol. 38, no. 9, pp. 1703-1715, 2003.

[18] M. I. M. Soares, "Biological denitrification of groundwater," Water, Air, and Soil Pollution, vol. 123, no. 1-4, pp. 183-193, 2000.

[19] I. F. Cheng, R. Muftikian, Q. Fernando, and N. Korte, "Reduction of nitrate to ammonia by zero-valent iron," Chemosphere, vol. 35, no. 11, pp. 2689-2695, 1997.

[20] G. Yang and H. Lee, "Chemical reduction of nitrate by nanosized iron: kinetics and pathways," Water Research, vol. 39, no. 5, pp. 884-894, 2005.

[21] M. Kumar and S. Chakraborty, "Chemical denitrification of water by zero-valent magnesium powder," Journal of Hazardous Materials, vol. 135, no. 1-3, pp. 112-121, 2006.

[22] F. He and D. Y. Zhao, "Preparation and characterization of a new class of starch-stabilized bimetallic nanoparticles for degradation of chlorinated hydrocarbons in water," Environmental Science and Technology, vol. 39, no. 9, pp. 3314-3320, 2005.

[23] B. Schrick, J. L. Blough, A. D. Jones, and T. E. Mallouk, "Hydrodechlorination of trichloroethylene to hydrocarbons using bimetallic nickel-iron nanoparticles," Chemistry of Materials, vol. 14, no. 12, pp. 5140-5147, 2002.

[24] F. He and D. Zhao, "Preparation and characterization of a new class of starch-stabilized bimetallic nanoparticles for degradation of chlorinated hydrocarbons in water," Environmental Science and Technology, vol. 39, no. 9, pp. 3314-3320, 2005.

[25] S. Anders, M. F. Toney, T. Thomson et al., "X-ray absorption and diffraction studies of thin polymer/FePt nanoparticle assemblies," Journal of Applied Physics, vol. 93, no. 10, p. 6299, 2003. 

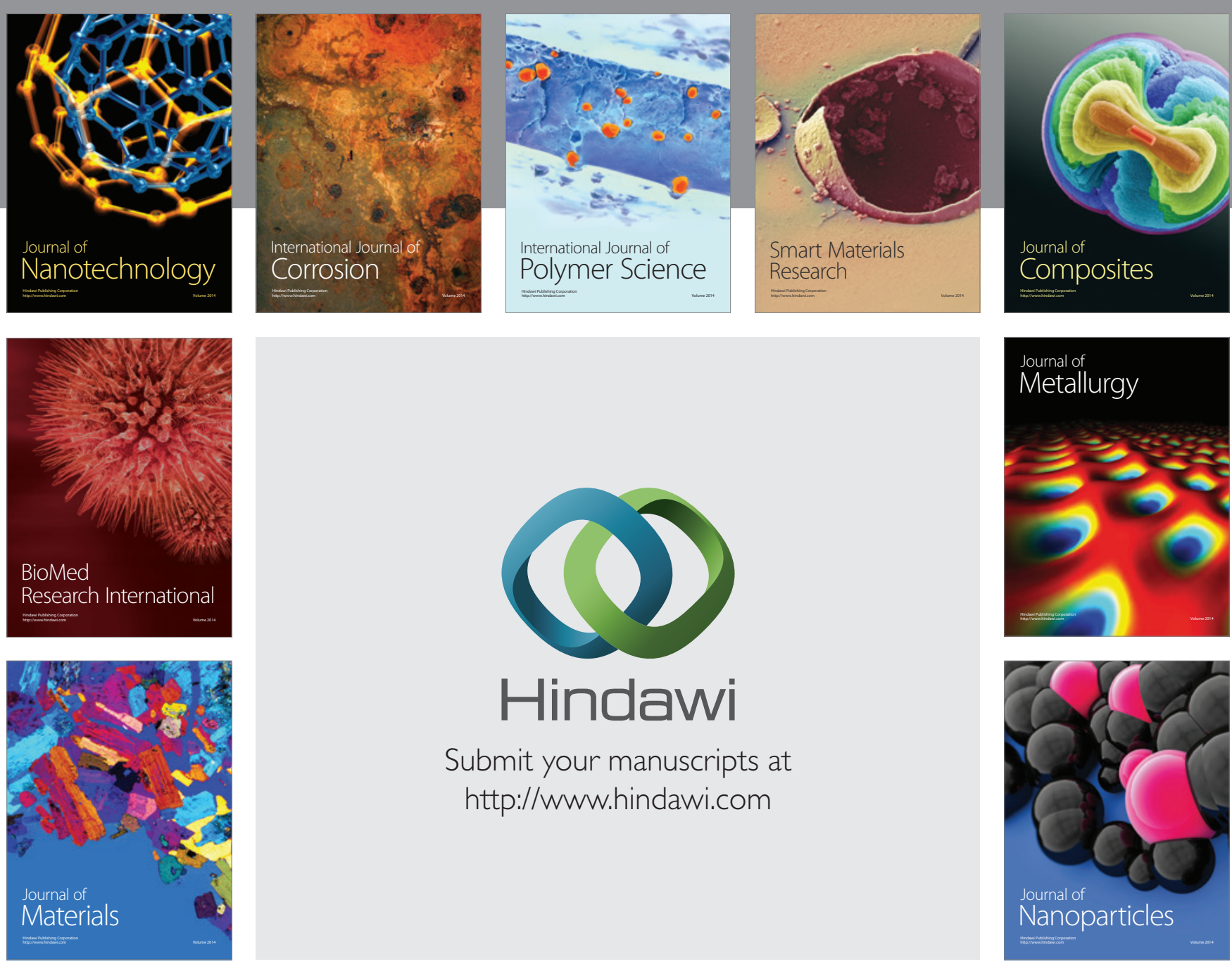

Submit your manuscripts at http://www.hindawi.com
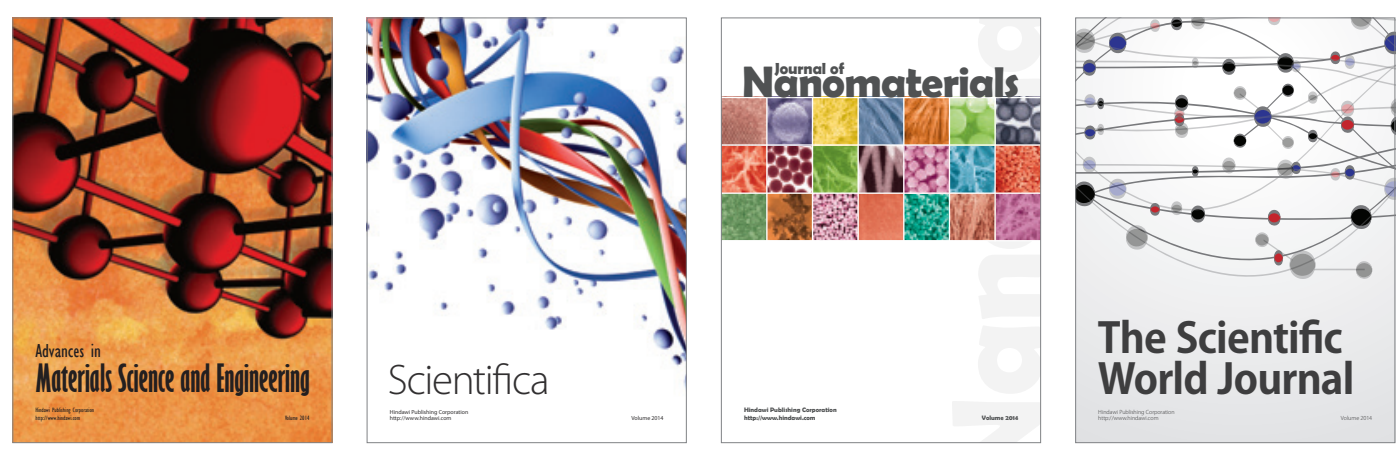

\section{The Scientific World Journal}
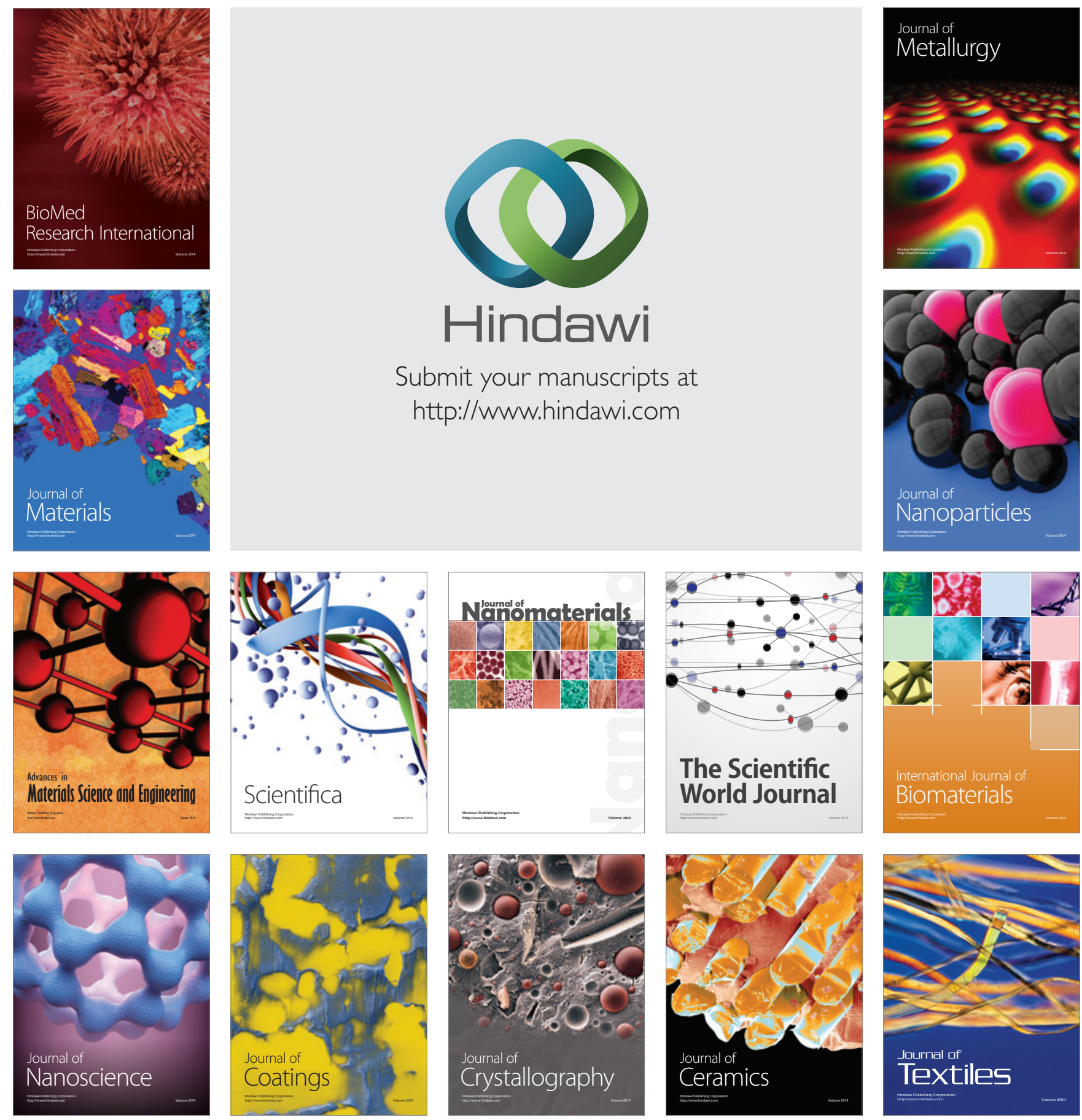